\title{
12. Synthesis of Blattellastanoside A, a Steroid Glucoside Isolated as the Aggregation Pheromone of the German Cockroach
}

\author{
By Kenji Mori and Kunio Fukamatsu \\ Department of Agricultural Chemistry, The University of Tokyo, \\ 1-1-1 Yayoi, Bunkyo-ku, Tokyo 113 \\ (Communicated by Masanao Matsui, M. J. A., March 12, 1993)
}

\begin{abstract}
Sitosterol (7) was converted to blattellastanoside A [5, 1-(6 $\alpha$-chloro- $4 \beta$, $5 \beta$-epoxy- $5 \beta$-stigmastan- $3 \beta$-yl)- $\beta$-D-glucopyranoside], the structure proposed for the arrestant component of the aggregation pheromone of the German cockroach, Blattella germanica L. Our synthetic 5 was identical with the natural product on the basis of ${ }^{1} \mathrm{H}$ and ${ }^{13} \mathrm{C}$ NMR spectral comparison, HPLC analysis and pheromone activity.
\end{abstract}

Key words: Aggregation pheromone; blattellastanoside A, synthesis of; German cockroach; glucoside; steroid.

The aggregation pheromone of the German cockroach (Blattella germanica L.) is excreted with its frass and marks its harboring place. ${ }^{1)}$ In 1990 Sakuma and Fukami identified the hydrochlorides of ammonia, methylamine, dimethylamine, trimethylamine, and 1-dimethylamino-2-methyl-2-propanol as the attractant components of the aggregation pheromone. ${ }^{2)}$ They then demonstrated the presence of the arrestant components in the frass. ${ }^{3)}$ Their work culminated in the isolation of two arrestant components, which were shown to be steroid glucosides and named as blattellastanosides $\mathrm{A}$ and $\mathrm{B} .{ }^{4)}$ The pheromone activity of the former was ca. 70 times stronger than that of the latter. Their structures were first proposed as 1 and 2, respectively (Fig. 1). ${ }^{4)}$ These proposals were modified shortly afterwards, and the structures 3 and $\mathbf{4}$ were the next candidates. ${ }^{5)}$ Our synthetic studies on the compounds related to 1-4 including a synthesis of 3, however, indicated the incorrectness of the proposed structures. ${ }^{6)}$

Very recently, Sakuma and Fukami reported new structures 5 and $\mathbf{6}$ for blattellastanosides A and B, respectively. ${ }^{7}$ Herein we announce the first synthesis of $\mathbf{5}$, which was proved to be identical with the natural blattellastanoside A by the comparison of its physical and biological properties. The outline of our synthesis is shown in Fig. 2. Commercially available stigmasterol was converted to $\beta$-sitosterol (7) in $70 \%$ overall yield (4 steps) according to Steele and Mosettig. $\left.{ }^{8}\right)$ Epoxidation of 7 with $m$-chloroperbenzoic acid (MCPBA) gave epoxy alcohol 8 as a 4:1 mixture of the desired $\alpha$-epoxide and its $\beta$-isomer in accord with the known result with cholesterol. ${ }^{9)}$ Treatment of $\mathbf{8}$ with hydrogen chloride in chloroform was followed by oxidation of the product to give nicely crystalline chloro ketol 9, m.p. $224-226^{\circ} \mathrm{C} ;[\alpha]_{\mathrm{D}}^{19}=+1.63^{\circ}\left(\mathrm{c}=0.57, \mathrm{CHCl}_{3}\right)$, in $64 \%$ yield after recrystallization. The $\beta$-and axial orientation of the chlorine substituent of 9 was supported by its ${ }^{1} \mathrm{H}$ NMR spectrum, in which the signal due to the equatorial proton at C-6 appeared at $\delta=3.84$ (br.t, $J=2.6 \mathrm{~Hz}$ ). Dehydration of 9 with hydrochloric acid in acetic acid caused epimerization at C-6 to give 10, m.p. $106-108^{\circ} \mathrm{C} ;[\alpha]_{\mathrm{D}}^{19}=+59.2^{\circ}\left(\mathrm{c}=0.98, \mathrm{CHCl}_{3}\right)$, with an axial proton at $\mathrm{C}-6$ $(\delta=4.67$, ddd, $J=12.6,5.0,1.8 \mathrm{~Hz}$ ). The $\alpha, \beta$-unsaturated ketone 10 was reduced with lithium tri(t-butoxy)aluminum hydride to generate a $\beta$ - and quasi-equatorial hydroxy group at C-3. The resulting allylic alcohol was epoxidized with MCPBA to give the corresponding $\beta$-epoxide $\mathbf{1 2}$ produced by cis-epoxidation as assisted by the $\beta$-oriented 
[Vol. 69(B),

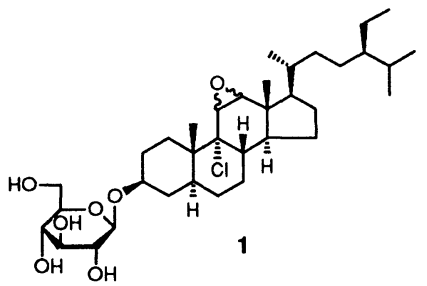

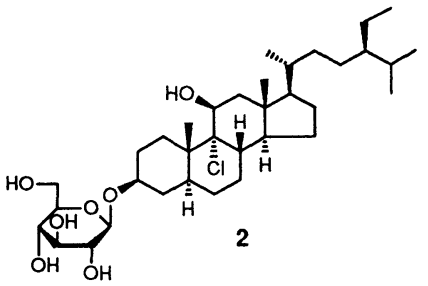

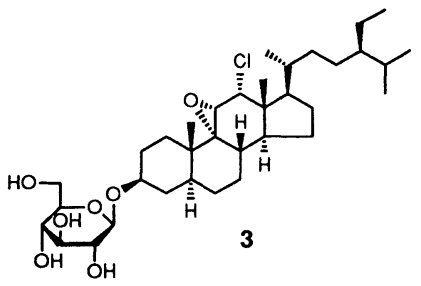

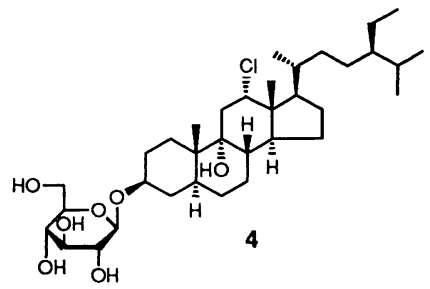

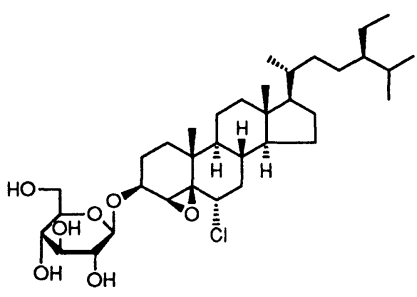

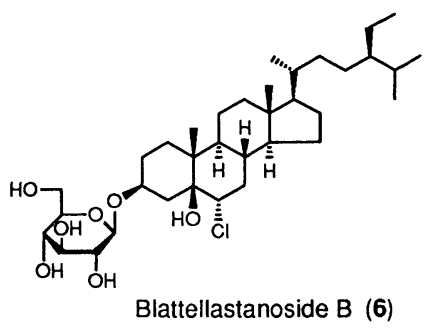

Fig. 1. Structures proposed for blattellastanosides A and B.

hydroxy group at C-3. The product 12 was acetylated and purified by silica gel chromatography to give pure acetate $11,[\alpha]_{\mathrm{D}}^{20}=-30.2^{\circ}\left(\mathrm{c}=1.00, \mathrm{CHCl}_{3}\right)$, in $71 \%$ yield from 10. Mild reduction of the purified 11 with diisobutylaluminum hydride gave back 12, $[\alpha]_{\mathrm{D}}^{19}=-14.6^{\circ}\left(\mathrm{c}=0.98, \mathrm{CHCl}_{3}\right)$, in $99 \%$ yield. The structure of 12 , especially the orientation of the epoxy and chlorine substituents, was confirmed by a single crystal $\mathrm{X}$-ray analysis of the corresponding ketone 13, m.p. $\left.96-97^{\circ} \mathrm{C} ;[\alpha]_{\mathrm{D}}^{20}=+57.7^{\circ}\left(\mathrm{c}=0.56, \mathrm{CHCl}_{3}\right){ }^{10}\right)$

$\beta$-Glucosidation of 12 could be achieved by the conventional Königs-Knorr method employing acetobromo-D-glucose (14) as the glucosyl donor to give 15, m.p. $136-137^{\circ} \mathrm{C}$; $[\alpha]_{\mathrm{D}}^{19}=-26.6^{\circ}\left(\mathrm{c}=1.01, \mathrm{CHCl}_{3}\right)$, in $70 \%$ yield. Finally, deacetylation of 15 with sodium methoxide in methanol-tetrahydrofuran gave, in $97 \%$ yield, 5 as leaflets, m.p. $164-166^{\circ} \mathrm{C}$; $[\alpha]_{\mathrm{D}}^{20}=-29.5^{\circ}(\mathrm{c}=1.03, \mathrm{EtOH})\left[\mathrm{ref}^{7}{ }^{7} \mathrm{~m} . \mathrm{p}\right.$. not reported; $\left.[\alpha]_{\mathrm{D}}^{20}=-23.0^{\circ}(\mathrm{c}=1.0, \mathrm{EtOH})\right]$. The identity of 5 with blattellastanoside A was confirmed on the basis of ${ }^{1} \mathrm{H}$ and ${ }^{13} \mathrm{C}$ NMR comparison, ${ }^{11)}$ HPLC analysis and bioassay. Our synthetic 5 was proved to be a potent arrestant pheromone against German cockroaches.

In conclusion, the structure of blattellastanoside $\mathrm{A}$ was established as $\mathbf{5}$ by the present synthesis. The overall yield of 5 from $\beta$-sitosterol (7) was $16 \%$ after 10 steps.

Acknowledgment. We thank Dr. M. Sakuma, Pesticide Research Institute (Kyoto University), for exchange of information, and the spectral and HPLC comparison as well as bioassay of our synthetic 5. Financial support of this work by Fuji Chemical Industries, Ltd. is acknowledged with thanks. 
<smiles>CCC(C)CCC(C)C1CCC2C1CCC21CCC2CC(O)CCC21C</smiles>

$\beta$-Sitosterol (7)

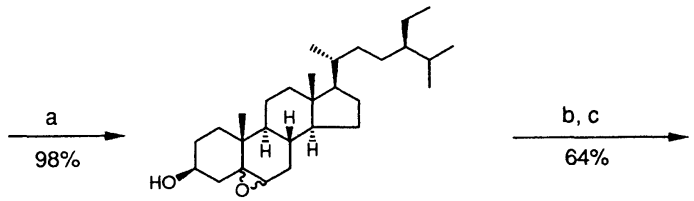

$8(\alpha / \beta$-epoxide $\fallingdotseq 4 / 1)$

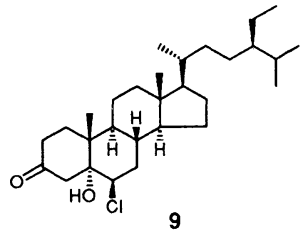

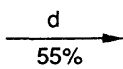

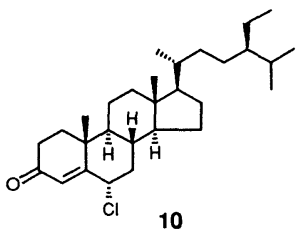<smiles>C[13CH3]</smiles>

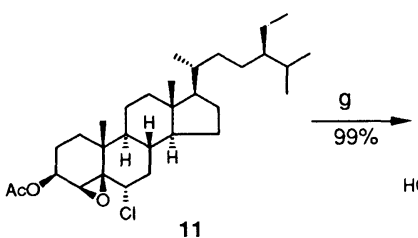

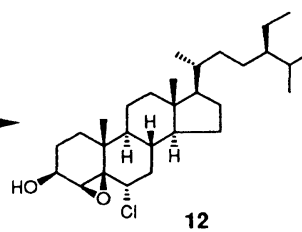<smiles>C[13CH3]</smiles>

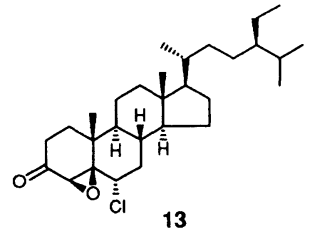

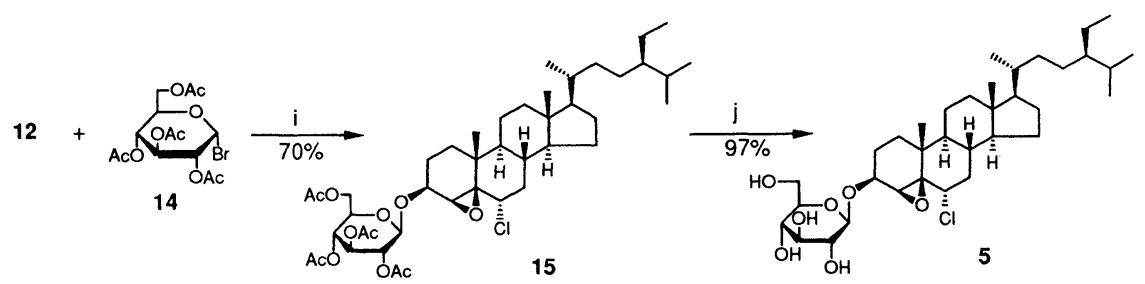

Fig. 2. Synthesis of blattellastanoside A. Reagents: (a) $\mathrm{MCPBA}, \mathrm{CH}_{2} \mathrm{Cl}_{2}$; (b) $\mathrm{HCl}$, $\mathrm{CHCl}_{3}$; (c) Jones $\mathrm{CrO}_{3}, \mathrm{Me}_{2} \mathrm{CO}$; (d) concd. $\mathrm{HCl}, \mathrm{AcOH}$; (e) $\mathrm{LiAl}(\mathrm{Ot}-\mathrm{Bu})_{3} \mathrm{H}$, THF; (f) $\mathrm{Ac}_{2} \mathrm{O}, \mathrm{Et}_{3} \mathrm{~N}$, DMAP, $\mathrm{CH}_{2} \mathrm{Cl}_{2}$; (g) $(i-\mathrm{Bu})_{2} \mathrm{AlH}, \mathrm{CH}_{2} \mathrm{Cl}_{2}$; (h) $\mathrm{PCC}, \mathrm{CH}_{2} \mathrm{Cl}_{2}$; (i) $\mathrm{Hg}(\mathrm{CN})_{2}$, $\mathrm{C}_{6} \mathrm{H}_{6} / \mathrm{MeNO}_{2}$; (j) NaOMe, MeOH/THF.

\section{References}

1) Ishii, S., and Kuwahara, Y.: Appl. Ent. Zool., 2, 203-217 (1967).

2) Sakuma, M., and Fukami, H.: ibid., 25, 355-368 (1990).

3) ——: ibid., 26, 223-235 (1991).

4) ——: Nippon Nōgeikagaku Kaishi, 66, 442 (1992).

5) Sakuma, M., and Fukami, H.: Presented as Poster-44 at the 9th Annual Meeting of International Society of Chemical Ecology, July 6-9, Kyoto, Japan, Abstract of Papers, p. 74 (1992).

6) Mori, K., Fukamatsu, K., and Kido, M.: Liebigs Ann. Chem. (to be submitted).

7) Sakuma, M., and Fukami, H.: Tetrahedron Lett. (in press).

8) Steele, J. A., and Mosettig, E:: J. Org. Chem., 28, 571-572 (1963).

9) Fieser, L. F., and Fieser, M.: Reagents in Organic Synthesis. John Wiley and Sons, Inc., New York, p. 136 (1967).

10) We thank Dr. M. Kido (Otsuka Pharmaceutical Co., Ltd.) for the X-ray analysis of 13. Details will be reported in the forthcoming full paper.

11) ${ }^{1} \mathrm{H}$ NMR spectrum of $5\left(300 \mathrm{MHz}, \mathrm{CDCl}_{3}\right): \quad \delta=0.68(\mathrm{~s}, 3 \mathrm{H}, 18-\mathrm{H}), 0.81(\mathrm{~d}, J=6.5 \mathrm{~Hz}, 3 \mathrm{H}$, $26-\mathrm{H}), 0.83(\mathrm{~d}, J=6.5 \mathrm{~Hz}, 3 \mathrm{H}, 27-\mathrm{H}), 0.85(\mathrm{t}, J=7.3 \mathrm{~Hz}, 3 \mathrm{H}, 29-\mathrm{H}), 0.91(\mathrm{~d}, J=6.5 \mathrm{~Hz}$, 
$3 \mathrm{H}, 21-\mathrm{H}), 0.80-1.48(\mathrm{~m}), 1.50-1.70(\mathrm{~m}), 1.80-1.95(\mathrm{~m}, 1 \mathrm{H}, 16 \alpha-\mathrm{H}), 2.00$ (br.d, $J=12.5$ $\mathrm{Hz}, 1 \mathrm{H}, 12 \beta-\mathrm{H}), 2.25(\mathrm{dt}, J=12.5,4.0 \mathrm{~Hz}, 1 \mathrm{H}, 7 \beta-\mathrm{H}), 3.35-3.50\left(\mathrm{~m}, 2 \mathrm{H}, 2{ }^{\prime}-\mathrm{H}\right.$ and 5 '- $\mathrm{H}$ ), 3.55-3.70 (m, 2H, 3'-H and 4'-H), 3.81 (d, $J=3.5 \mathrm{~Hz}, 1 \mathrm{H}, 4-\mathrm{H}), 3.80-3.95\left(\mathrm{~m}, 2 \mathrm{H}, 6{ }^{\prime}-\mathrm{H}\right)$, 4.25 (br.s, $\left.\mathrm{W}_{1 / 2}=10.5 \mathrm{~Hz}, 1 \mathrm{H}, 3-\mathrm{H}\right), 4.44$ (dd, $\left.J=12.5,4.0 \mathrm{~Hz}, 1 \mathrm{H}, 6-\mathrm{H}\right), 4.60$ (d, J=7.6 $\mathrm{Hz}, 1 \mathrm{H}, 1$ '-H). ${ }^{13} \mathrm{C}$ NMR spectrum of 5 (125 $\left.\mathrm{MHz} \mathrm{CDCl}_{3}\right): \quad 1 ; \delta \mathrm{c} 30.1,2 ; 23.5,3 ; 72.2$, 4; 56.1 , $5 ; 67.5,6$; 58.5, 7; 41.7, 8; 35.8, $9 ; 48.3$, 10; 38.3, 11; 21.4, 12; 39.5, 13; 42.7, 14; 55.5, $15 ; 24.2,16 ; 28.1,17 ; 56.2,18 ; 12.0,19 ; 18.6,20 ; 36.1,21 ; 18.6,22 ; 33.9,23 ; 26.2,24 ; 45.8$, $25 ; 29.1 ; 26 ; 19.8,27 ; 19.0,28 ; 23.1 ; 29 ; 12.0$, 1'; 101.8, 2'; 73.6, 3'; 76.3, 4'; 69.8, 5'; 75.7, $6 ; 61.9$. 